\title{
Correction: Novel stochastic framework for automatic segmentation of human thigh MRI volumes and its applications in spinal cord injured individuals
}

\author{
Samineh Mesbah, Ahmed M. Shalaby, Sean Stills, Ahmed Soliman, Andrea Willhite, Susan \\ J. Harkema, Enrico Rejc, Ayman S. El-Baz
}

The fourth author's name is incorrect. The correct name is: Ahmed Soliman. The correct citation is: Mesbah S, Shalaby AM, Stills S, Soliman A, Willhite A, Harkema SJ, et al. (2019) Novel stochastic framework for automatic segmentation of human thigh MRI volumes and its applications in spinal cord injured individuals. PLoS ONE 14(5): e0216487. https://doi.org/10.1371/ journal.pone.0216487.

\section{Reference}

1. Mesbah S, Shalaby AM, Stills S, Soliman AM, Willhite A, Harkema SJ, et al. (2019) Novel stochastic framework for automatic segmentation of human thigh MRI volumes and its applications in spinal cord injured individuals. PLoS ONE 14(5): e0216487. https://doi.org/10.1371/journal.pone.0216487 PMID: 31071158

\section{f open ACCEss}

Citation: Mesbah S, Shalaby AM, Stills S, Soliman A, Willhite A, Harkema SJ, et al. (2019) Correction: Novel stochastic framework for automatic segmentation of human thigh MRI volumes and its applications in spinal cord injured individuals. PLoS ONE 14(7): e0219810. https://doi.org/10.1371/ journal.pone.0219810

Published: July 16, 2019

Copyright: @ 2019 Mesbah et al. This is an open access article distributed under the terms of the Creative Commons Attribution License, which permits unrestricted use, distribution, and reproduction in any medium, provided the original author and source are credited. 